\title{
Surgical techniques for sciatica due to herniated disc, a systematic review
}

\author{
Wilco C. H. Jacobs • Mark P. Arts • Maurits W. van Tulder • \\ Sidney M. Rubinstein · Marienke van Middelkoop - Raymond W. Ostelo • \\ Arianne P. Verhagen • Bart W. Koes · Wilco C. Peul
}

Received: 17 November 2011 / Revised: 1 June 2012/ Accepted: 25 June 2012/Published online: 20 July 2012

(C) The Author(s) 2012. This article is published with open access at Springerlink.com

\begin{abstract}
Introduction Disc herniation with sciatica accounts for five percent of low-back disorders but is one of the most common reasons for spine surgery. The goal of this study was to update the Cochrane review on the effect of surgical techniques for sciatica due to disc herniation, which was last updated in 2007.

Materials and methods In April 2011, we conducted a comprehensive search in CENTRAL, MEDLINE, EMBASE, CINAHL, PEDRO, ICL, and trial registries. We also checked the reference lists and citation tracking results of each retrieved article. Only randomized controlled trials (RCT) of the surgical management of sciatica due to disc herniation were included. Comparisons
\end{abstract}

W. C. H. Jacobs $(\bowtie) \cdot$ W. C. Peul

Department of Neurosurgery, Leiden University Medical Center, Albinusdreef 2, PO Box 9600, 2300 RC Leiden, The Netherlands e-mail: w.c.h.jacobs@lumc.nl

M. P. Arts · W. C. Peul

Department of Neurosurgery, Medical Center Haaglanden, Lijnbaan 32, 2512 VA The Hague, The Netherlands

M. W. van Tulder · R. W. Ostelo

Department of Health Sciences, Faculty of Earth and Life Science \& EMGO Institute for Health and Care Research, VU University, De Boelelaan 1085, 1081 HV Amsterdam, The Netherlands

M. W. van Tulder $\cdot$ S. M. Rubinstein · R. W. Ostelo Department of Epidemiology and Biostatistics, EMGO-Institute for Health and Care Research, VU University Medical Center, Amsterdam, The Netherlands

M. van Middelkoop · A. P. Verhagen - B. W. Koes Department of General Practice, Erasmus MC,

University Medical Center Rotterdam, PO Box 2040,

3000 CA Rotterdam, The Netherlands including chemonucleolysis and prevention of scar tissue or comparisons against conservative treatment were excluded. Two review authors independently selected studies, assessed risk of bias of the studies and extracted data. Quality of evidence was graded according to the GRADE approach.

Results Seven studies from the original Cochrane review were included and nine additional studies were found. In total, 16 studies were included, of which four had a low risk of bias. Studies showed that microscopic discectomy results in a significantly, but not clinically relevant longer operation time of $12 \mathrm{~min}$ (95\% CI 2-22) and shorter incision of $24 \mathrm{~mm}$ (95\% CI 7-40) compared with open discectomy, but did not find any clinically relevant superiority of either technique on clinical results. There were conflicting results regarding the comparison of tubular discectomy versus microscopic discectomy for back pain and surgical duration.

Conclusions Due to the limited amount and quality of evidence, no firm conclusions on effectiveness of the current surgical techniques being open discectomy, microscopic discectomy, and tubular discectomy compared with each other can be drawn. Those differences in leg or back pain scores, operation time, and incision length that were found are clinically insignificant. Large, high-quality studies are needed, which examine not only effectiveness but cost-effectiveness as well.

Keywords Herniated disc - Sciatica $\cdot$ Surgery . Discectomy $\cdot$ Systematic review

\section{Introduction}

Management of sciatica that is caused by a herniated disc varies considerably. Patients are commonly treated in 


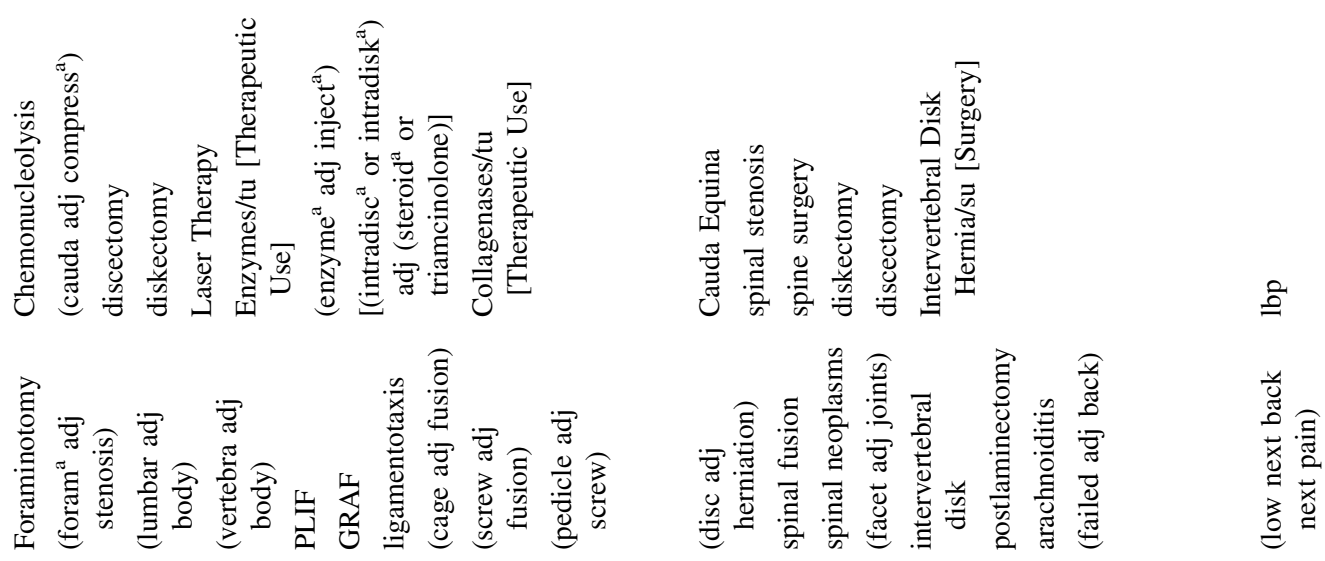

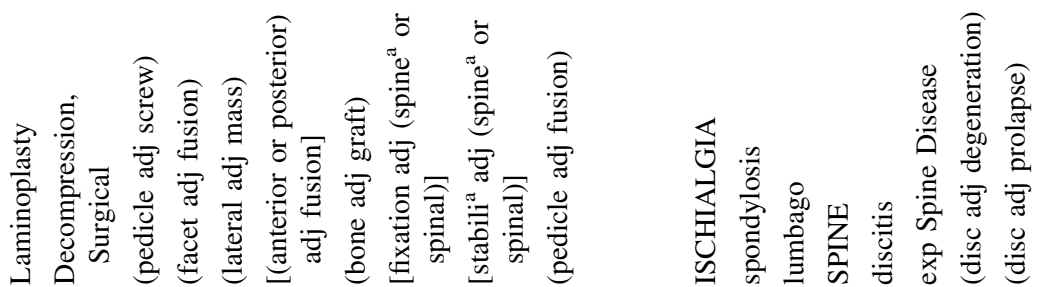

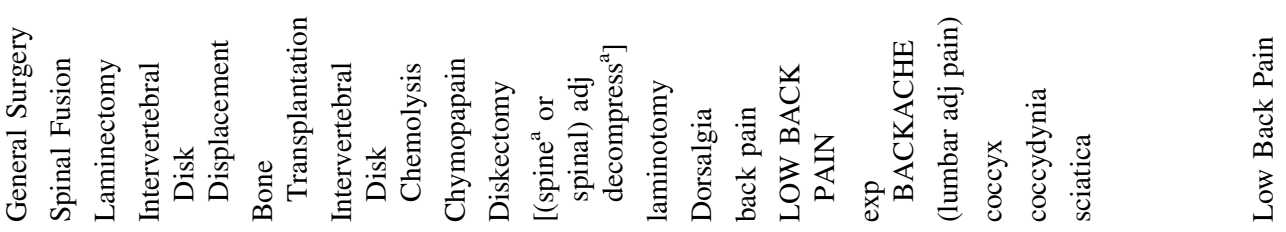

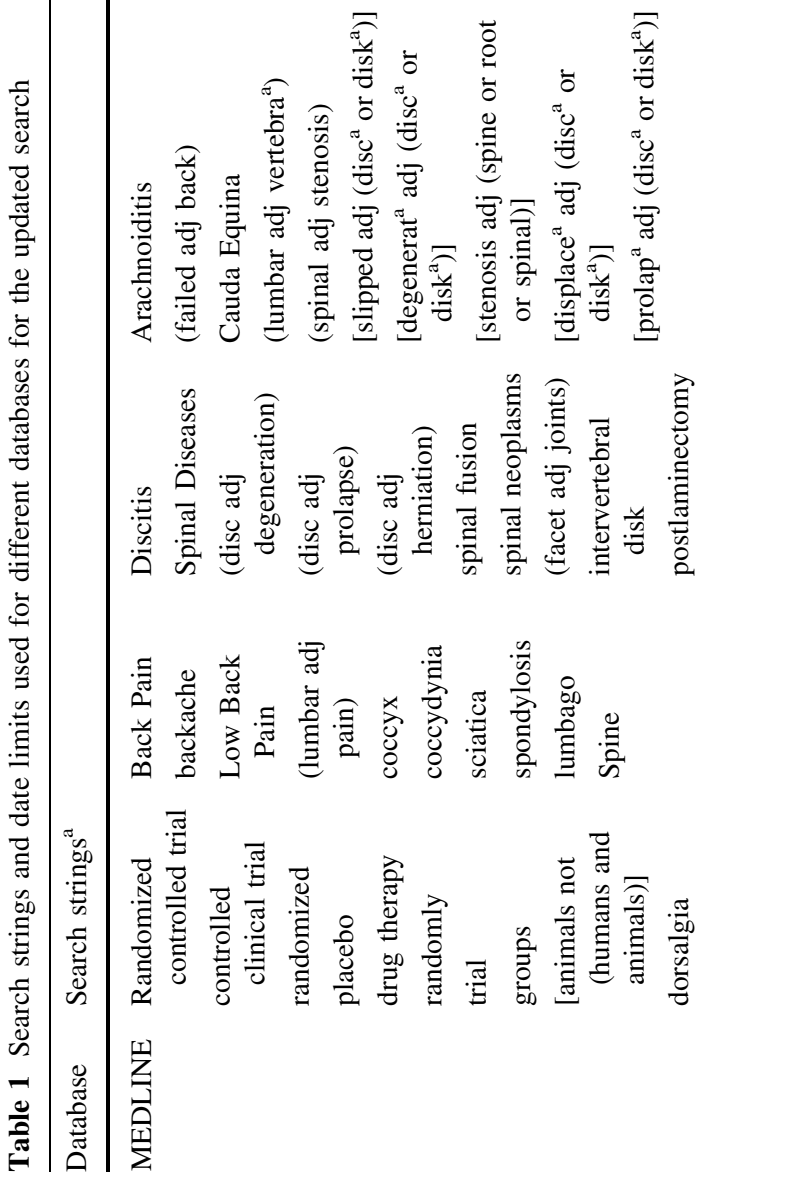

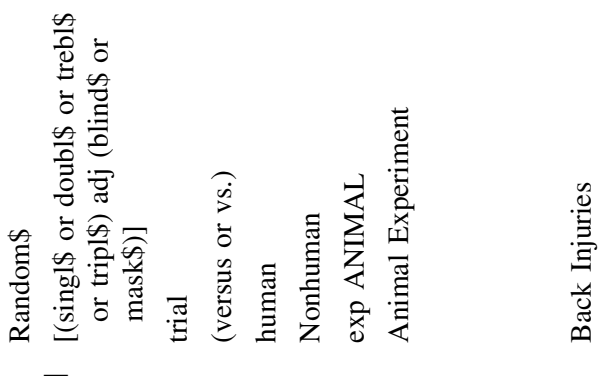

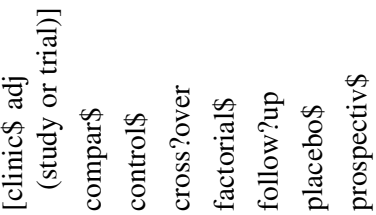

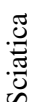

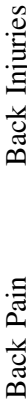

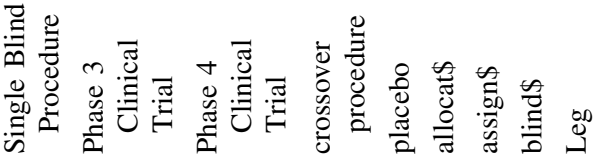

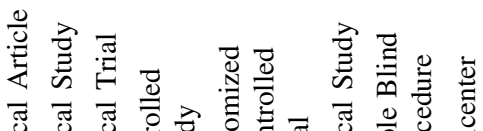

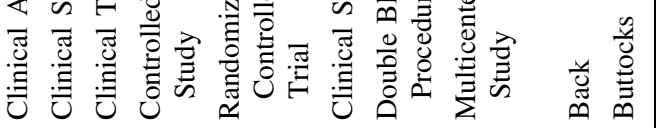

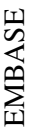

冢 


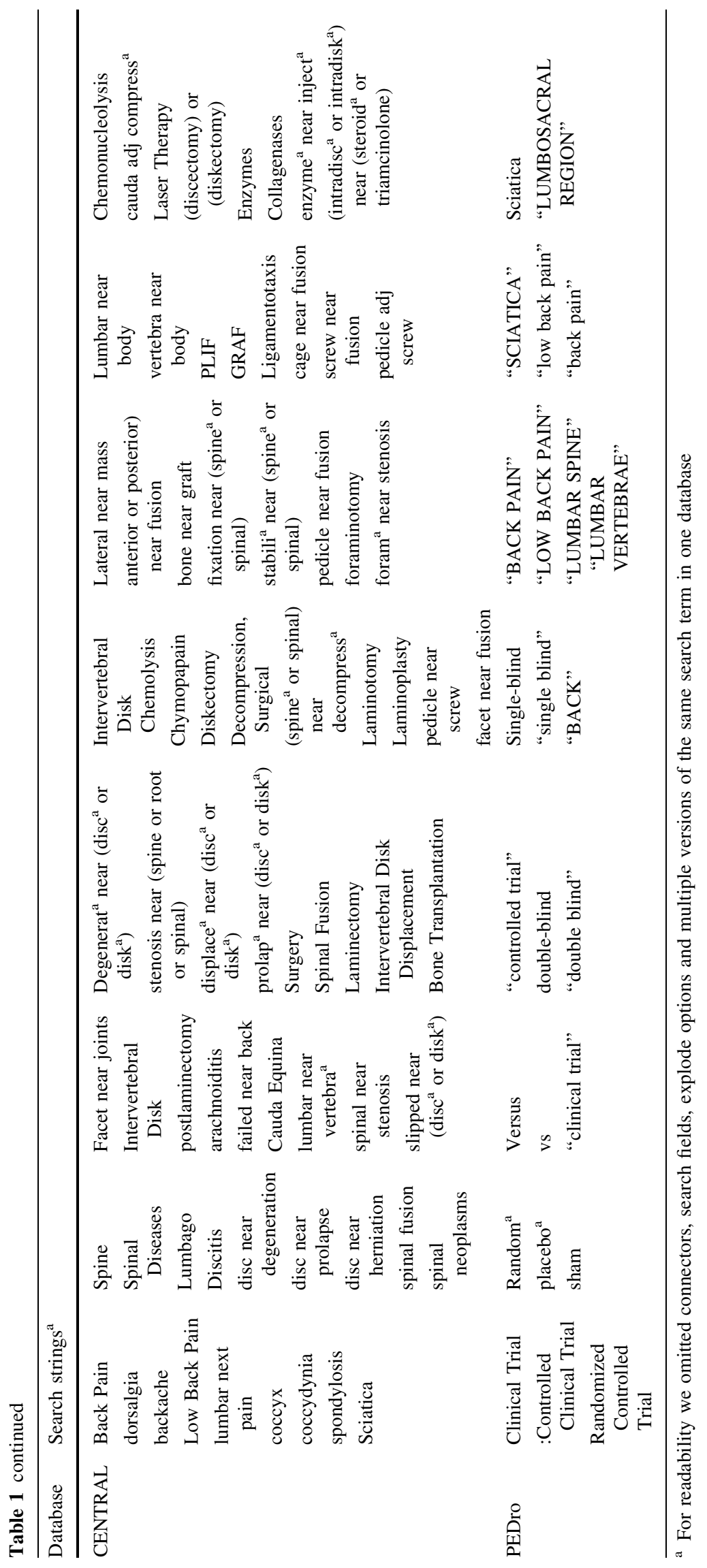


Table 2 Selection criteria

\begin{tabular}{|c|c|}
\hline \multirow[t]{4}{*}{ Types of studies } & Randomized controlled trials (RCT) \\
\hline & No fatal methodological flaw \\
\hline & Full-text journal article \\
\hline & Published in a peer reviewed journal \\
\hline Types of participants & Patients with sciatica due to disc herniation, who have indications for surgical intervention \\
\hline Types of interventions & $\begin{array}{l}\text { Comparisons between all types of surgical intervention were included, such as discectomy, micro-endoscopic- } \\
\text { discectomy, automated percutaneous discectomy, nucleoplasty and laser discectomy. Any modifications to these } \\
\text { interventional procedures were included, but alternative therapies such as nutritional or hormonal therapies were } \\
\text { excluded }\end{array}$ \\
\hline \multirow{8}{*}{$\begin{array}{l}\text { Types of outcome } \\
\text { measures }\end{array}$} & All available outcomes were included, but patient centered outcomes were considered of primary interest: \\
\hline & Pain (Average on VAS or similar, or proportion improved) \\
\hline & Recovery (Proportion of patients reporting recovery and/or as determined by a clinician) \\
\hline & Function (Proportion of patients who had an improvement in function measured on a disability or quality of life scale) \\
\hline & Return to work \\
\hline & Rate of subsequent low back surgery \\
\hline & $\begin{array}{l}\text { Measures of objective physical impairment: Spinal flexion, improvement in straight leg raise, alteration in muscle } \\
\text { power and change in neurological signs }\end{array}$ \\
\hline & $\begin{array}{l}\text { Adverse complications: Early: Damage to spinal cord, cauda equina, dural lining, a nerve root, or any combination; } \\
\text { infection; vascular injury (including subarachnoid hemorrhage); allergic reaction to chymopapain; medical } \\
\text { complications; death. Late: Chronic pain, altered spinal biomechanics, instability or both; adhesive arachnoiditis; } \\
\text { nerve root dysfunction; myelocele; recurrent symptoms of sciatica due to disc herniation }\end{array}$ \\
\hline
\end{tabular}

primary care, but a small proportion is referred to secondary care and may eventually undergo surgery if complaints persist for at least 6 weeks. Conservative treatment for sciatica is primarily aimed at pain reduction, either by analgesics or by reducing pressure on the nerve root. However, consensus is lacking as to whether surgery is useful or not in the absence of serious neurologic deficits. There seems to be consensus that surgery is indicated in carefully selected patients with sciatica and presence of a herniated lumbar disc [21, 23, 34]. In most Western countries, especially in the United States, rates of spine surgery are high [14]. The primary rationale of any form of surgery for sciatica due to herniated disc is to relieve nerve root irritation or compression, but the results should be balanced against the likely natural history and the results of conservative care. A recent systematic review indicated that surgery resulted in faster recovery when compared with conservative care, but for the longer term (12 months) no differences were found [31]. The usual indication for surgery is to provide more rapid relief of pain and disability in the minority of patients whose recovery is unacceptably slow $[21,38]$.

The most common type of surgery is microscopic discectomy, which is defined as surgical removal of part of the disc, performed with the use of an operating microscope or other magnifying tools. Most studies refer to Caspar [11], Yasargil [50], and Williams [49] when discectomy is performed with a microscope; and to Foley and Smith [15] or Greiner-Perth et al. [24] when discectomy is performed with tubular, muscle splitting, retractor systems, and endoscope. However, some have returned to using a microscope, while retaining the less invasive muscle splitting approach of Foley and Smith [15]. There is also uncertainty regarding the relative benefits and harms of different surgical techniques, as was concluded in the 2007 Gibson and Waddell [21] Cochrane review on lumbar disc herniation. This review needs to be updated as several new randomized trials have come to our attention comparing surgical techniques. The objective of this systematic review was to assess the effectiveness of the various surgical techniques for discectomy, such as open, microscopic or tubular discectomy.

\section{Methods}

Search methods for identification of studies

In the previous Cochrane review for lumbar disc prolapse [20, 21], 40 RCTs, up to January 1st, 2007 were identified. We aimed to update the Cochrane review limited to surgical techniques for lumbar disc herniation with sciatica. For this update, we used the original search strategy in the following databases to identify additional studies:

- Computer-aided searching of MEDLINE, EMBASE, CINAHL, CENTRAL, PEDRO, and ICL from January 2005 to April 2011 using the search strings previously published [19, 21] was performed by the Cochrane Back Review Group. Search strategy is represented in Table 1. No language restrictions were used. 
Table 3 Criteria for risk of bias assessment

Question Criteria for "Yes" Judgment

A 1. Was the method of randomization adequate?

A random (unpredictable) assignment sequence. Examples of adequate Yes/No/ methods are coin toss, rolling a dice, drawing of ballots with the study Unsure group labels from a dark bag, computer-generated random sequence, preordered sealed envelops, sequentially ordered vials

Examples of inadequate methods are alternation, birth date, social insurance/ security number, and hospital registration number

B 2. Was the treatment allocation concealed?

Assignments are generated by an independent person not responsible for determining the eligibility of the patients. This person has no information about the persons included in the trial and has no influence on the assignment sequence or on the eligibility decision of the patient

C 3. Was the patient blinded to the intervention?

The index and control groups are indistinguishable for the patients

Yes/No/

Unsure

4. Was the care provider blinded to the intervention?

5. Was the outcome assessor blinded to the intervention?

The index and control groups are indistinguishable for the care providers

Yes/No/

Unsure

- For patient-reported outcomes with adequately blinded patients

Yes/No/

- For outcome criteria that supposes a contact between participants and

Unsure outcome assessors: the blinding procedure is adequate if patients are blinded, and the treatment or adverse effects of the treatment cannot be noticed during examination

- For outcome criteria that do not suppose a contact with participants: the blinding procedure is adequate if the treatment or adverse effects of the treatment cannot be noticed during the assessment

- For outcome criteria that are clinical or therapeutic events that will be determined by the interaction between patients and care providers, in which the care provider is the outcome assessor: the report needs to be free of selective outcome reporting

D 6. Was the drop-out rate described and acceptable?

The number of participants who were included in the study but did not complete the observation period or were not included in the analysis are described and reasons are given and are $<20 \%$ for short-term and $<30 \%$ for long-term follow-up

7. Were all randomized participants analyzed in the group to which they were allocated?

E 8. Are reports of the study free of suggestion of selective outcome reporting?

F 9. Were the groups similar at baseline regarding the most important prognostic indicators?

10. Were co-interventions avoided or similar?

All randomized patients are reported/analyzed in the group they were allocated to by randomization for the most important moments of effect measurement (minus missing values) irrespective of non-compliance and co-interventions

Yes/No/

Unsure

$\mathrm{Yes} / \mathrm{No} /$

Unsure

Yes/No/

Unsure

The groups have to be similar at baseline regarding demographic factors, duration and severity of complaints, percentage of patients with

Yes/No/ neurological symptoms, and value of main outcome measure(s)

Unsure

There were no co-interventions or they were similar between the index and $\mathrm{Yes} / \mathrm{No} /$ control groups

Unsure

11. Was the compliance acceptable in all groups?

12. Was the timing of the outcome assessment similar in all groups?

The compliance with the interventions is acceptable, based on the reported intensity, duration, number and frequency of sessions for both the index intervention and control intervention(s). For single-session interventions

Yes/No/ (for ex: surgery), this item is irrelevant

Timing of outcome assessment was identical for all intervention groups and $\mathrm{Yes} / \mathrm{No} /$ for all important outcome assessments

Unsure

- Communication with members of the Cochrane Back Review Group and other international experts.

- Checking reference lists and citation tracking of all papers identified by the above strategies.

- The International Standard Randomized Controlled Trial Number register (ISRCTN) [2], Clinical Trials register [1], USFDA trial register [3] were searched from their beginning at January 1st, 2007 up to April 2011 , to identify ongoing studies.

Criteria for considering studies for this review

Selection criteria for inclusion of studies into the review are given in Table 2. First, we evaluated the studies included in 
Fig. 1 Flow chart for inclusion of studies

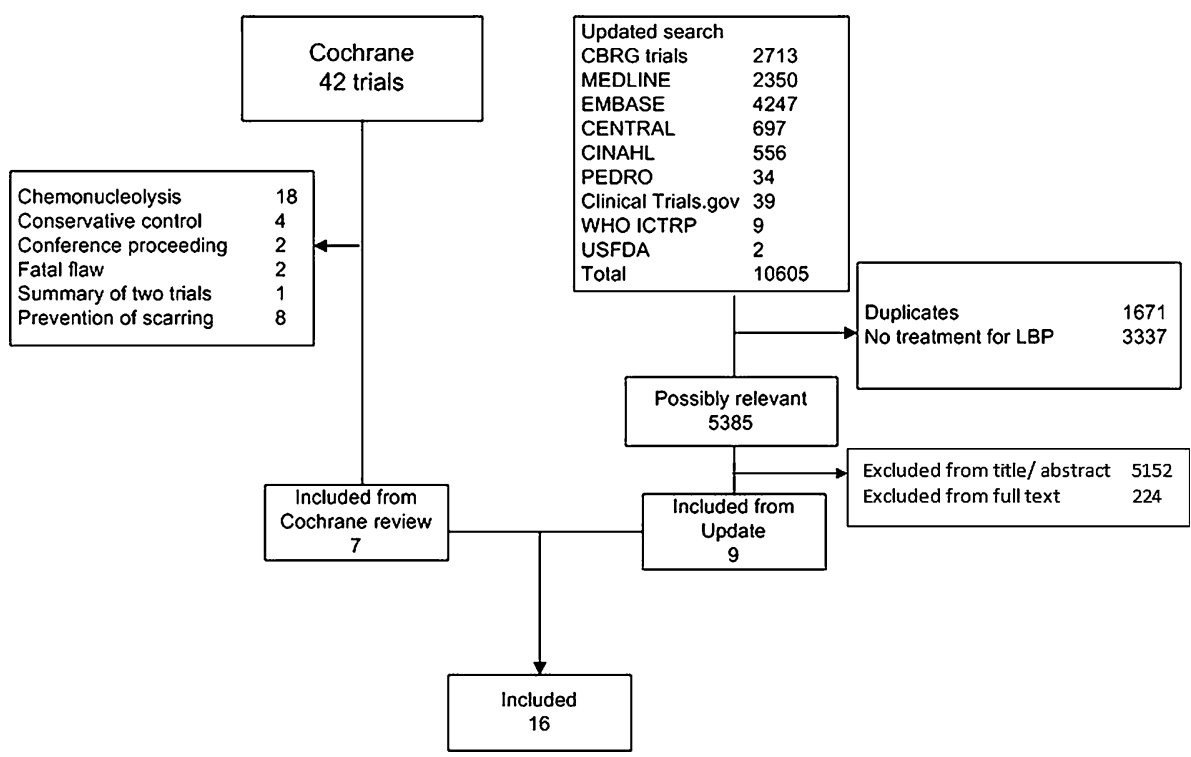

the original Cochrane review against the new criteria (excluding scar tissue and chemonucleolysis trials). At present, chemonucleolysis is neither available nor widely used in most western countries due to safety concerns, namely the risk of allergic reactions to the enzyme that can result in anaphylactic shock-in some patients with fatal consequences. Consequently, we excluded the studies on chemonucleolysis from this update. The comparison of conservative versus surgical treatment was included in a separate, recently published, review [31] and was thus not included here. From the additional electronic search, two review authors (WP, MA) working independently from one another examined titles and abstracts. Full articles were obtained if eligibility could not be ascertained from the title or abstract. Titles and abstracts could be blinded for authors and affiliations, but we did not pursue this with retrieved articles. The two reviewers discussed their selection to meet consensus about inclusions, and a third reviewer was consulted (BK) if consensus was not reached.

\section{Risk of bias assessment}

Risk of bias was assessed with the 12-item criteria list recommended by the Cochrane Back Review Group (CBRG) [17]. Criteria are given in Table 3 including operationalization. The items were scored with 'yes' $(+)$, 'no' $(-)$, or 'unsure' (?). Studies were categorized as having a 'low risk of bias' when at least six of the 12 criteria were met, and the study had no serious methodological flaws such as extensive loss to follow-up or invalidating trial stop. The risk of bias was assessed independently by two review authors (SR, MvM), who again met to reach consensus. If consensus could not be reached, a third review author (BK) was consulted to resolve the disagreement. The risk of bias assessment in the Cochrane review [20] did not include all items of the current tool used within the Cochrane Back Review Group [17]. Selective outcome reporting, similarity of groups at baseline, and co-interventions were additionally assessed for this review.

Data collection and analysis

Included studies were categorized under separate comparisons with clinically homogeneous characteristics. An a priori list of items was used for the data extraction, consisting of both descriptive data (e.g., study population, type of interventions, outcome parameters used) and quantitative data regarding the primary and secondary outcome measures. One reviewer (WJ) extracted the data and entered the data into Review Manager (RevMan, Version 5.1. The Cochrane Collaboration, 2011). We aimed at analyzing the parameters of surgical morbidity (operation duration ( $\mathrm{min}$ ), blood loss (ml), incision length (mm), length of stay (days)), and clinical outcomes (low back pain (VAS), leg pain (VAS), and other clinical outcomes (for example, Oswestry, JOA, SF-36, Return to Work). Pain (low back or leg) is regarded the primary outcome. The main endpoint for clinical outcome was defined as 2 years, Where possible, an attempt was made to categorize patients according to their symptom duration (less than 6 weeks, 6 weeks to 6 months, more than 6 months), by their response to previous conservative therapy and type of disc herniation. The overall quality of the evidence was graded as 'High', 'Moderate', 'Low', or 'Very low', according to the GRADE approach [25]. This means that the overall quality of evidence was initially regarded as 'High', but was downgraded if there were limitations in design according to the risk of bias assessment, inconsistency, indirectness, imprecision, or publication bias. For comparisons with only one reported outcome, 


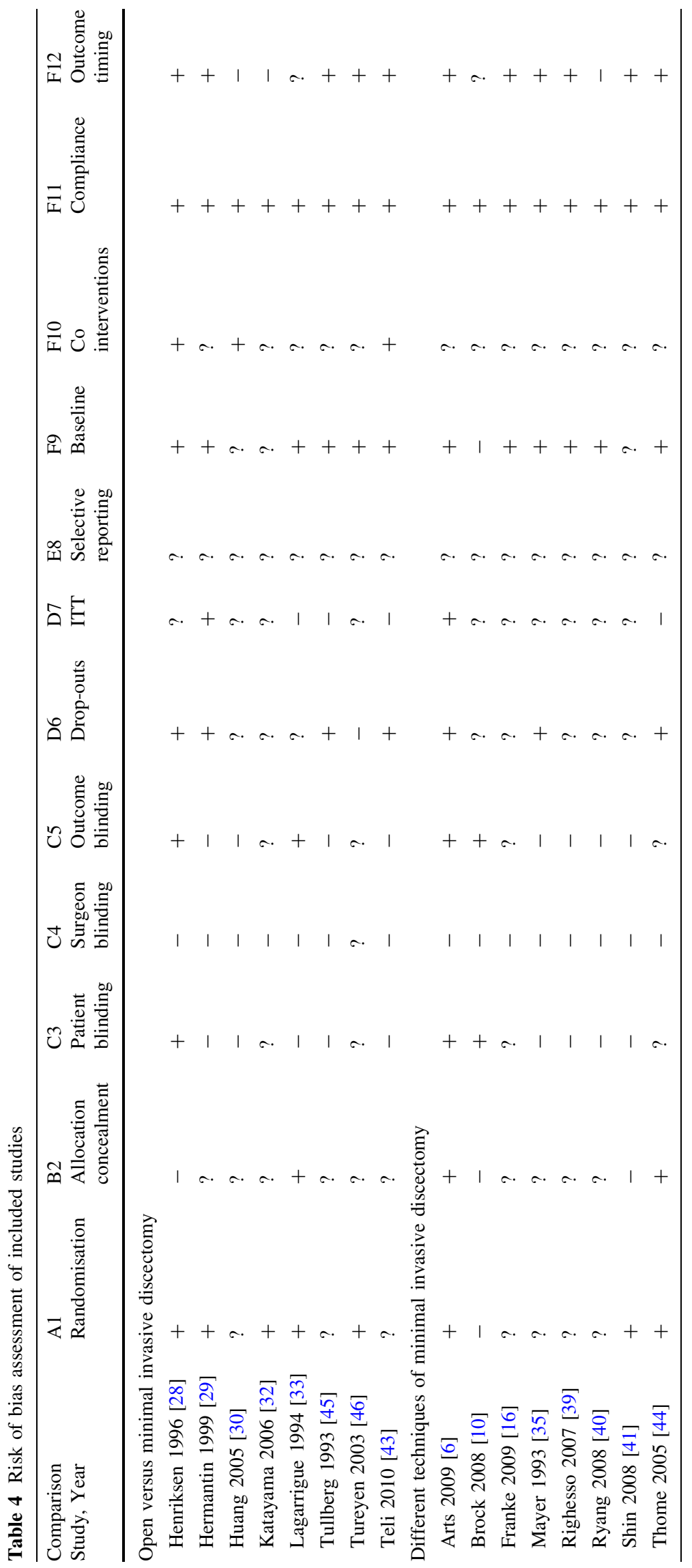


Table 5 Quality of evidence for reported outcomes

\begin{tabular}{|c|c|c|c|c|c|c|c|c|c|c|}
\hline \multirow{2}{*}{$\begin{array}{l}\text { Comparison } \\
\text { Outcome }\end{array}$} & \multirow[t]{2}{*}{ Studies } & \multirow[t]{2}{*}{ Patients } & \multicolumn{5}{|c|}{ Grade limitations } & \multicolumn{2}{|c|}{ Summary of findings } & \multirow{2}{*}{$\begin{array}{l}\text { Quantitative } \\
\text { Pooled } \\
\text { effect }\end{array}$} \\
\hline & & & $\begin{array}{l}\text { Publication } \\
\text { bias }\end{array}$ & Inconsistency & Indirectness & Imprecision & $\begin{array}{l}\text { Risk } \\
\text { of } \\
\text { bias }\end{array}$ & Effect & Quality & \\
\hline \multicolumn{11}{|c|}{ Open (OD) versus minimal invasive discectomy (MID) 6 studies } \\
\hline $\begin{array}{l}\text { Surgery } \\
\text { duration } \\
(\min )\end{array}$ & 6 & 612 & + & + & + & + & - & $\mathrm{OD}<\mathrm{MID}$ & Moderate & $\begin{array}{c}\text { MD } 12.2 \\
(2.20 \text { to } \\
22.3)\end{array}$ \\
\hline $\begin{array}{l}\text { Length of } \\
\text { stay } \\
\text { (days) }\end{array}$ & 5 & 452 & + & + & + & + & - & $\mathrm{OD}<>\mathrm{MID}$ & Moderate & $\begin{array}{c}\mathrm{MD}-0.06 \\
\quad(-0.10 \text { to } \\
+0.21)\end{array}$ \\
\hline $\begin{array}{l}\text { Blood } \\
\text { loss }\end{array}$ & 2 & 179 & - & + & + & - & - & OD ? MID & Very low & \\
\hline Incision & 3 & 353 & + & - & + & + & - & $\mathrm{OD}>\mathrm{MID}$ & Low & \\
\hline $\begin{array}{l}\text { Leg pain } \\
(\mathrm{mm} \\
\text { VAS })\end{array}$ & 4 & 453 & + & + & + & + & - & $\mathrm{OD}>\mathrm{MID}$ & Moderate & $\begin{array}{c}\mathrm{MD}-2.01 \\
\quad(-3.44 \text { to } \\
-0.57)\end{array}$ \\
\hline $\begin{array}{l}\text { Back pain } \\
\text { (mm } \\
\text { VAS) }\end{array}$ & 3 & 419 & - & - & + & + & - & OD ? MID & Very low & \\
\hline $\begin{array}{l}\text { Return to } \\
\text { work }\end{array}$ & 3 & 254 & $?$ & - & + & + & - & OD ? MID & Very low & \\
\hline \multicolumn{11}{|c|}{ Tubular (TD) versus microscopic discectomy (MID) 7 studies } \\
\hline $\begin{array}{l}\text { Surgery } \\
\text { duration } \\
(\min )\end{array}$ & 6 & 718 & + & - & + & - & - & TD ? MID & Very low & \\
\hline $\begin{array}{l}\text { Blood } \\
\text { loss }\end{array}$ & 3 & 130 & - & + & + & - & - & TD ? MID & Very low & \\
\hline $\begin{array}{l}\text { Length of } \\
\text { stay } \\
\text { (days) }\end{array}$ & 4 & 528 & + & + & + & - & - & $\mathrm{TD}<>\mathrm{MID}$ & Low & \\
\hline Incision & 3 & 260 & + & + & + & $?$ & - & $\mathrm{TD}<\mathrm{MID}$ & $\begin{array}{l}\text { Low/ } \\
\text { Moderate }\end{array}$ & $\begin{array}{l}\text { SD sparsely } \\
\text { reported }\end{array}$ \\
\hline $\begin{array}{l}\text { Leg pain } \\
(\mathrm{mm} \\
\text { VAS })\end{array}$ & 3 & 548 & - & - & + & + & - & TD ? MID & Very low & \\
\hline $\begin{array}{l}\text { Back pain } \\
(\mathrm{mm} \\
\text { VAS })\end{array}$ & 4 & 703 & + & - & + & + & - & TD $<>$ MID & Low & \\
\hline Oswestry & 3 & 225 & $?$ & + & + & - & - & TD ? MID & Very low & \\
\hline SF36 & 3 & 548 & $?$ & + & + & + & - & TD ? MID & Low & \\
\hline
\end{tabular}

${ }^{a}<$ or $>$ Effect is superior for one of both treatments; $<>$ None of either treatments is superior; ? unclear relative effectiveness due to conflicting results

$M D$ Mean difference, $O R$ odds ratio

or with only one study, no grading was performed. With sufficient clinically and statistically homogeneous and sufficiently comparable and adequately reported outcomes, data were pooled and forest plots were generated using Revman. Random effects estimates were used for all analyses. To identify publication bias, funnel plots were examined. Because of the limited clinical value, no pooled analyses were performed for low and very low quality of evidence, conflicting evidence, or indirect evidence.

\section{Results}

Search and selection results

Seven of the 42 studies from the original Cochrane review were included. We excluded 30 studies because the interventions evaluated did not meet our new, limited, selection criteria pertaining to surgical techniques. Studies were excluded because they examined some form of 


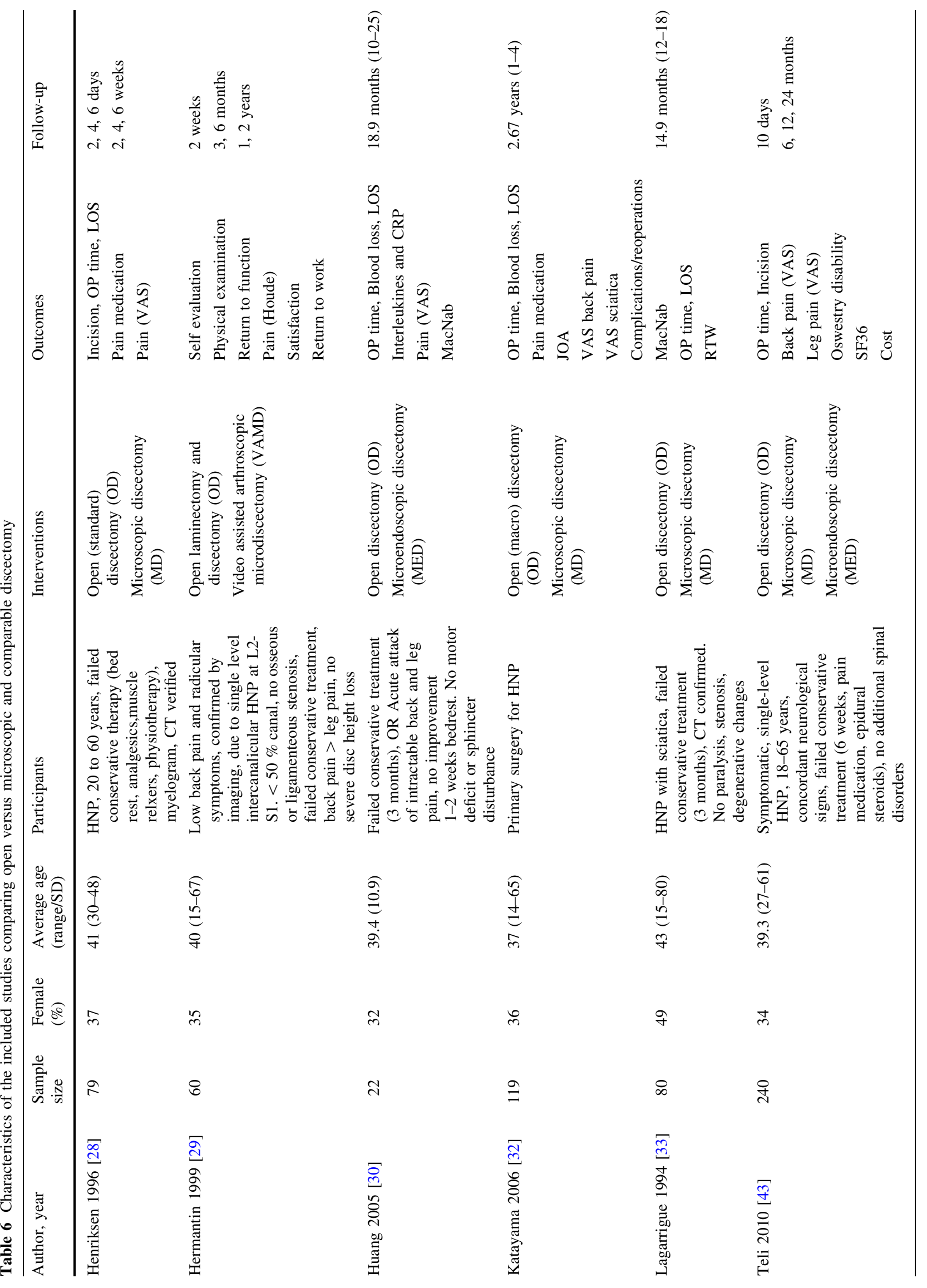


chemonucleolysis (18), because they compared conservative with surgical interventions (4), or because they examined any type of barrier membrane for prevention of scar tissue (8). Additionally, we excluded five studies from the original review, being two conference proceedings [37, 42]; one summary of two included studies [18]; and two studies with a fatal flaw due to trial stop after interim analysis [12], and due to trial stop after only $10 \%$ of the sample size [26, 27].

We identified seven additional studies published since publication of the previous review [6, 10, 16, 39-41, 43] and two studies that were published in 2006 or before but for unclear reasons not included in the Cochrane review $[32,46]$. The study from Arts et al. [6] was reported in four additional publications with analysis of effect modifiers [5], assessment of muscle injury [4], 2-year results [7], and cost-effectiveness analysis [47]. Two additional papers reported long-term follow-up of the Thome et al. [44] study concerning clinical [9] and radiological [8] results. Details of the search are presented in Fig. 1. There were no ongoing studies found. A total of 16 studies were included.

Risk of bias assessment

Risk of bias assessments are reported in Table 4. Four studies were considered to have a low risk of bias study (six positive items). Randomization was adequate in half of the studies and allocation concealment was adequately described in only three studies. Outcome assessor blinding and patient blinding was used in a quarter of the studies. Selective reporting is doubtful in most studies, as rarely a prepublished protocol could be found. Compliance is by definition graded 'Yes' (+), as this review deals with a surgical technique. Quality of evidence for the separate outcomes for all comparisons is given in Table 5 .

\section{Effects of interventions}

We distinguished comparisons between open and minimal invasive discectomy and comparisons between different techniques for minimal invasive discectomy. It was not possible to analyze patients according to duration of their symptoms, previous conservative treatment, type of disc herniation, or indications for surgery, as too few data were available. Many studies provided limited information on complications. All quality of evidence was downgraded because of the risk of bias in the studies: further downgrading is noted in the text.

Open versus minimal invasive discectomy

Eight studies compared open discectomy (OD) versus minimal invasive techniques such as use of loupe 


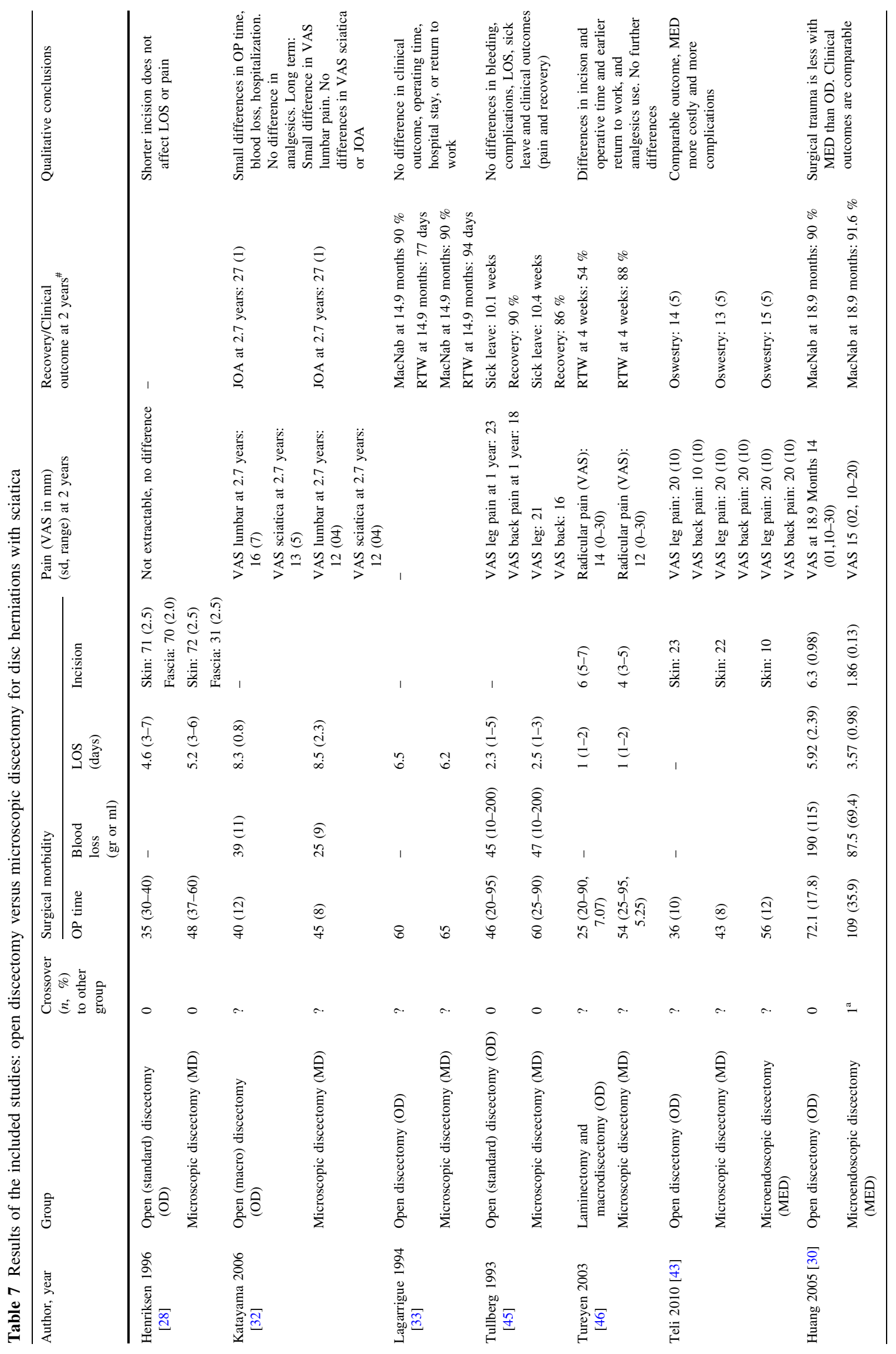




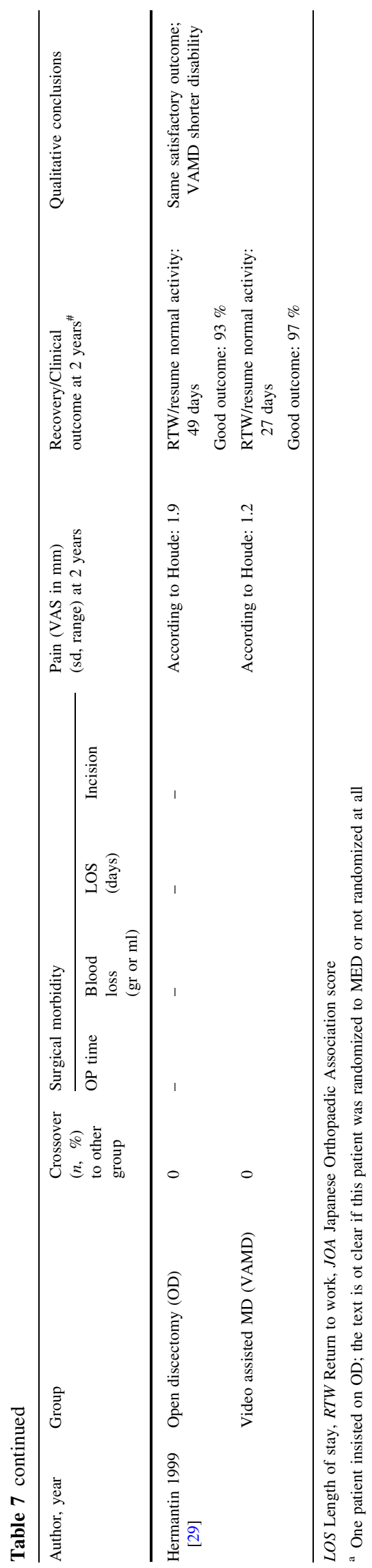

magnification or microscope (MID), video-assisted microscopic discectomy (VAMD) or micro-endoscopic discectomy (MED). One of the studies compared three types of surgery: open, microscopic, and micro-endoscopic discectomy and could be included in three comparisons. Characteristics of included studies are presented in Table 6. The results of these studies are given in Table 7 .

Six studies with 612 patients (five with high risk of bias) compared the classical open (or standard- or macro-) discectomy with microscopic discectomy [28, 32, 33, 43, 45, 46]. Leg pain was reported in four studies with 453 patients. There was moderate quality of evidence that postoperative leg pain was statistically significantly less for microscopic discectomy by $2.01 \mathrm{~mm}$ (95\% CI $0.57-3.44 ; p=0.006$; see Fig. 2). The follow-up of these studies ranged from 1 to 2.7 years. A higher proportion of patients with return to work was found at 4 weeks for microscopic discectomy [46] in one study $(n=114)$, whereas two other studies $(n=140)$ found no difference at 10 weeks [45] and 15 months [33]. All six studies found an increased operating time for microscopic discectomy with a pooled effect of $12.2 \min (95 \%$ CI 2.20-22.3; $p=0.02$; moderate quality of evidence; see Fig. 3). Length of stay was reported in five studies with 452 patients, but no differences were found. The mean difference was 0.06 days in favor of open discectomy ( $95 \% \mathrm{CI}-0.10$ to +0.21 days; $p=0.47$; moderate quality of evidence; see Fig. 4). Blood loss was reported in two studies, in one study $(n=119)$ microscopic discectomy resulted in less blood loss [32], while in the other study $(n=60)$ there was no difference [45]. Length of incision was reported in three studies $(n=353)$ and found to be shorter for microscopic discectomy in two studies [28, 46]. The quality of evidence for blood loss had to be downgraded due to risk of bias, publication bias and imprecision and was 'very low'. Quality of evidence for incision was 'low' due to risk of bias and inconsistency (Table 5). Therefore, these results were not pooled.

Two studies compared open with micro-endoscopic discectomy (MED) [30, 43]. Huang et al. [30] reported results of a very small, high risk of bias, study $(n=22)$. There were no differences in leg pain severity and MacNab criteria between the groups. The MED group had shorter postoperative hospital stay (3.6 vs. 5.9 days) and less intraoperative blood loss (88 versus $190 \mathrm{ml}$ ) compared with the open discectomy group, but duration of the operation was longer (109 vs. $72 \mathrm{~min}$ ). Teli et al. [43] showed in a larger high risk of bias study $(n=220)$ that the MED group compared with open and microscopic discectomy suffered more dural tears $(6 / 70,2 / 72,2 / 70$, respectively), root injuries $(2 / 70,0 / 72,0 / 70$, respectively), and recurrent herniations $(8 / 70,3 / 72,2 / 70$, respectively).

One low risk of bias study $(n=60)$ found that patients who had received video-assisted arthroscopic microdiscectomy 


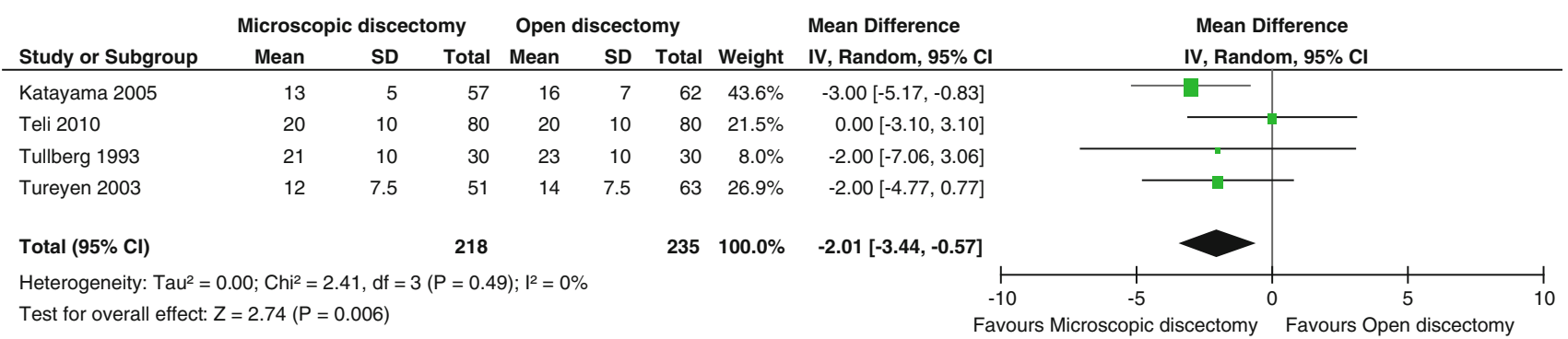

Fig. 2 Forest plot for VAS leg pain between microscopic discectomy and open discectomy

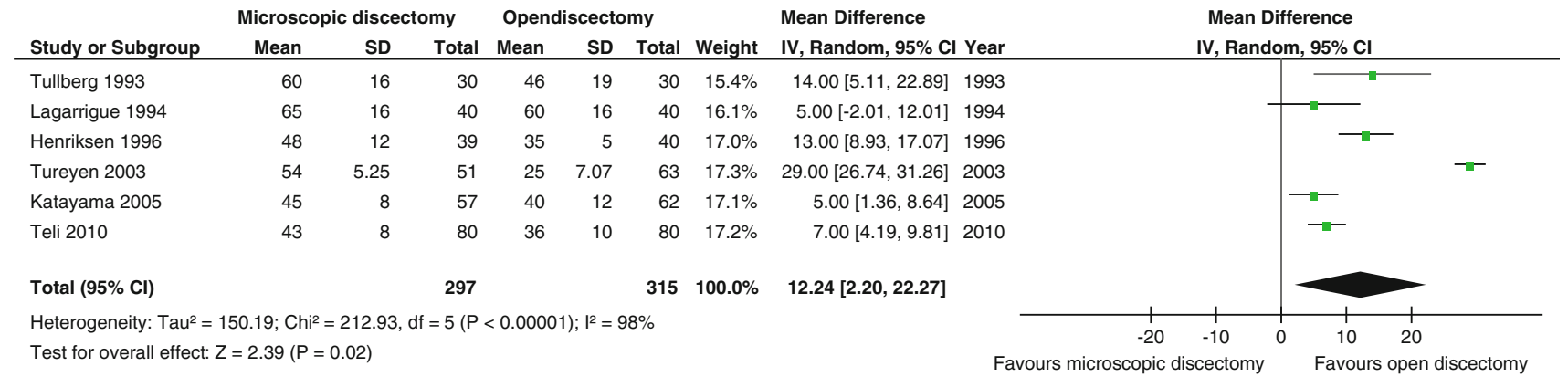

Fig. 3 Forest plot for operating time between microscopic discectomy and open discectomy

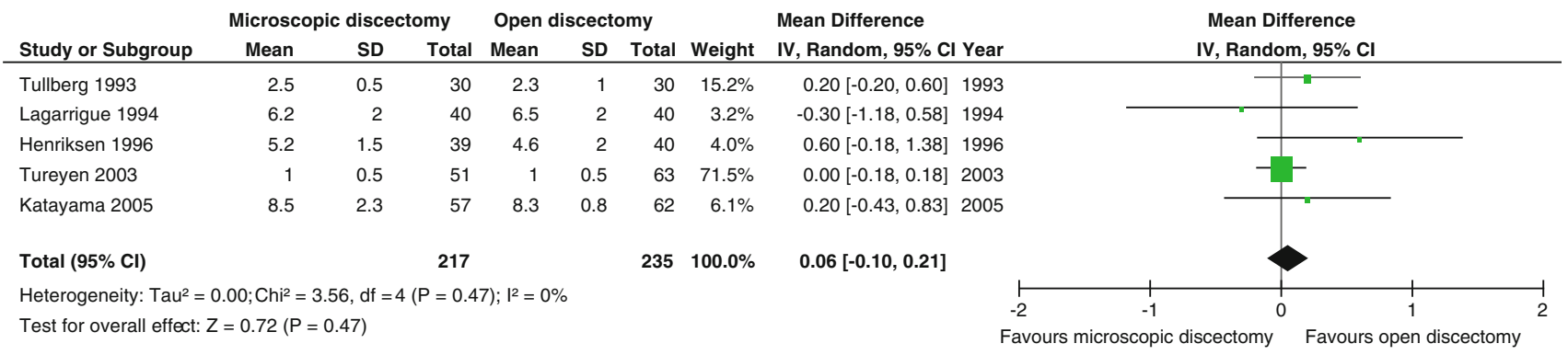

Fig. 4 Forest plot for length of stay between microscopic discectomy and open discectomy

had similar satisfactory outcomes (based on self evaluation, return to work, and physical exam) compared with open laminotomy and discectomy, but patients who had had an arthroscopic microdiscectomy had a shorter duration of postoperative disability ( 27 vs. 49 days) and had a lower narcotic use score [29].

\section{Various types of microdiscectomy}

Nine studies with 1,047 patients evaluated different approaches for less invasive discectomy, such as use of loupe magnification or microscopic discectomy (MD), micro-endoscopic discectomy (MED), tubular microscopic discectomy, microscopic assisted percutaneous nucleotomy (MPN), minimal access trocar/microsurgical microdiscectomy (MAMD), percutaneous endoscopic discectomy or sequestrectomy. We analyzed the comparisons between these techniques, keeping the differences in muscle damage and differences in use of microscope or endoscope in mind. Characteristics of included studies are presented in Table 8. The results of these studies are given in Table 9.

Seven (six with high risk of bias) studies with 923 patients compared tubular discectomy with conventional microscopic discectomy [6, 10, 16, 39-41, 43]. Of these, four used an endoscope [39-41, 43]. One study found a faster improvement in pain scores for tubular discectomy before discharge [41], while the only low risk of bias study found a slightly better pain score for conventional discectomy at 2 years [6]. All other outcomes for pain as measured with VAS, for functioning as measured with Oswestry or Roland-Morris score, or for quality of life measured with SF36 were not significantly different between the two surgical techniques. In Shin et al. [41], baseline values for back pain were not comparable. In one 


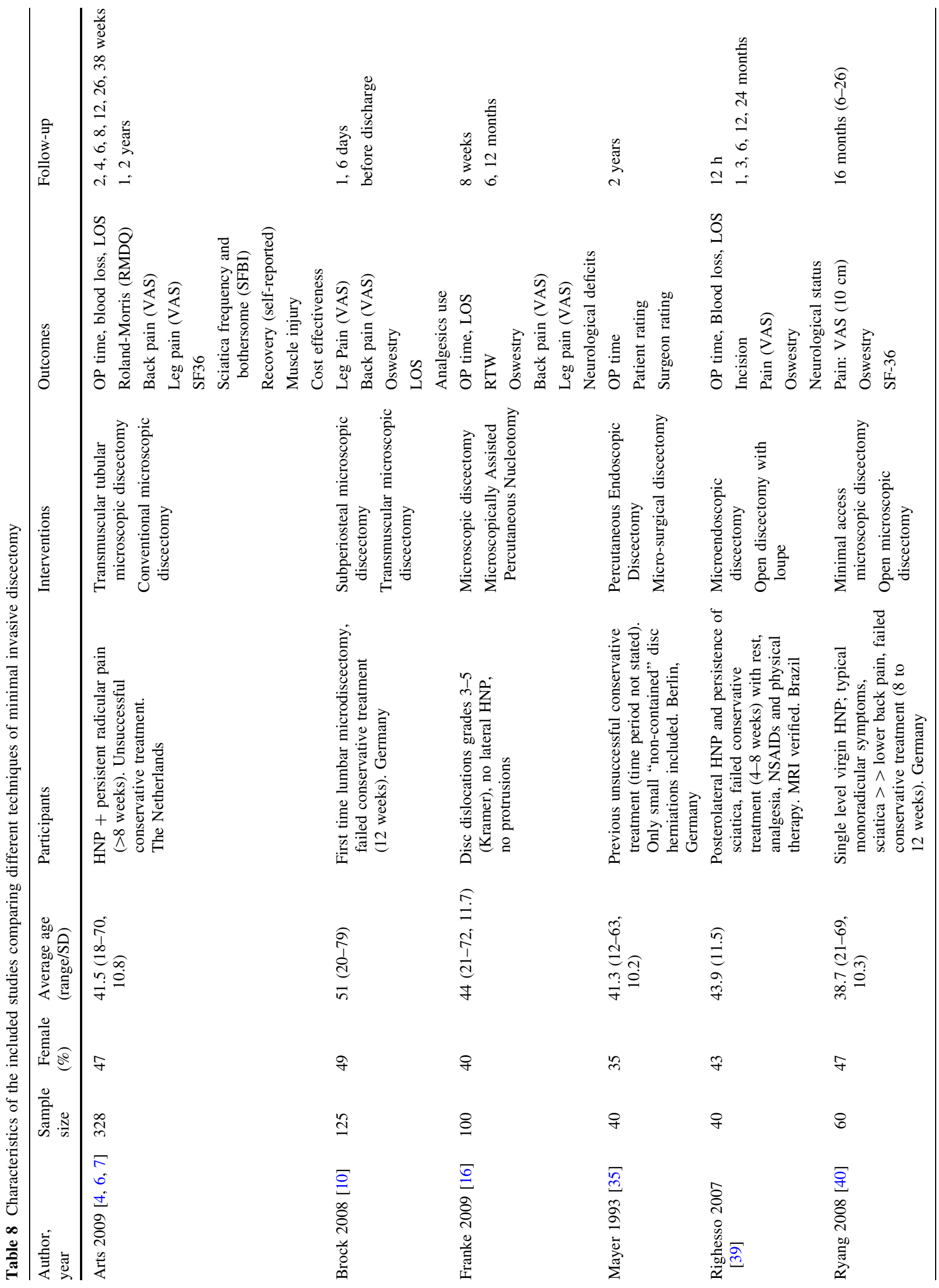




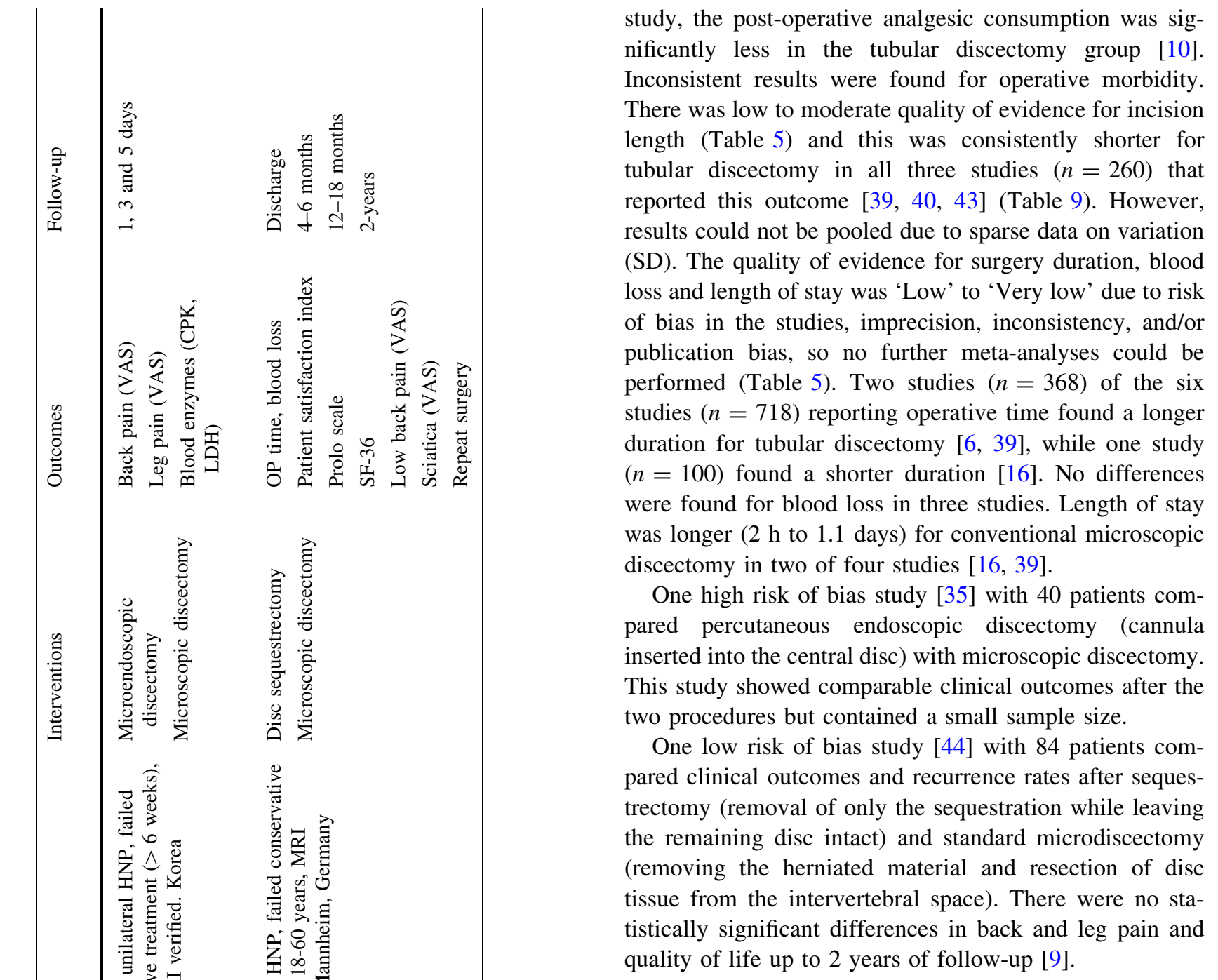

\section{Discussion}

Limited quality and amount of evidence were found that microscopic discectomy results in at least an equal clinical outcome compared with open discectomy. There was only moderate quality evidence that microscopic discectomy resulted in a clinically irrelevant reduction of leg pain of $2 \mathrm{~mm}$ (on a 100-mm scale) compared with open discectomy at 1-2 years, which is regarded clinically relevant at minimal $15 \mathrm{~mm}$ according to Ostelo et al. [31]. For back pain and return to work, the evidence is of very low quality and suffers from inconsistency, risk of bias, and possibly publication bias. Concerning operative morbidity, microscopic discectomy results in decreased incision length compared with open discectomy while the surgical duration increased with microscopic discectomy.

When tubular discectomy was compared with microscopic discectomy, there were conflicting results for the main outcomes of surgical duration and for back pain from 


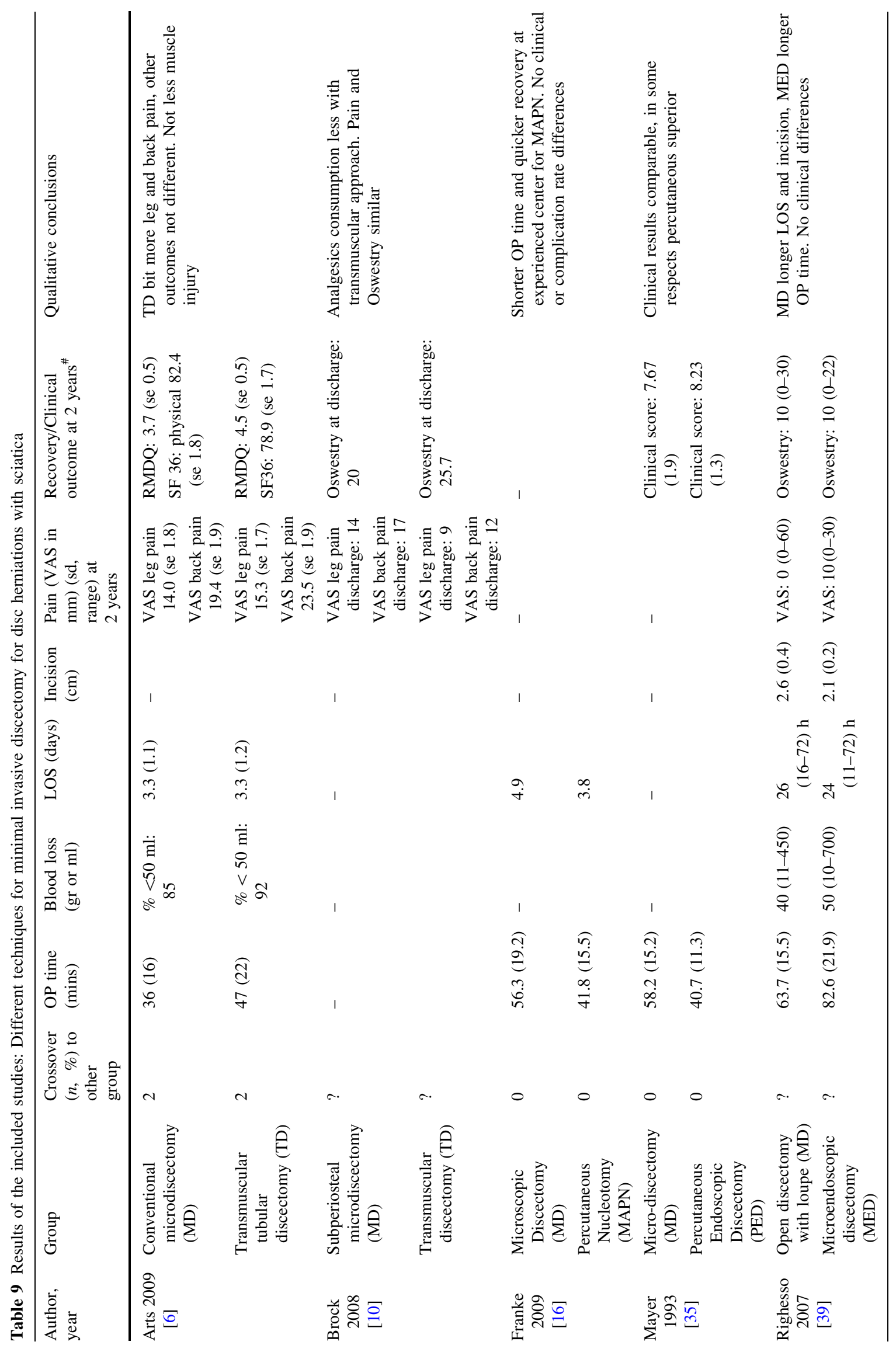




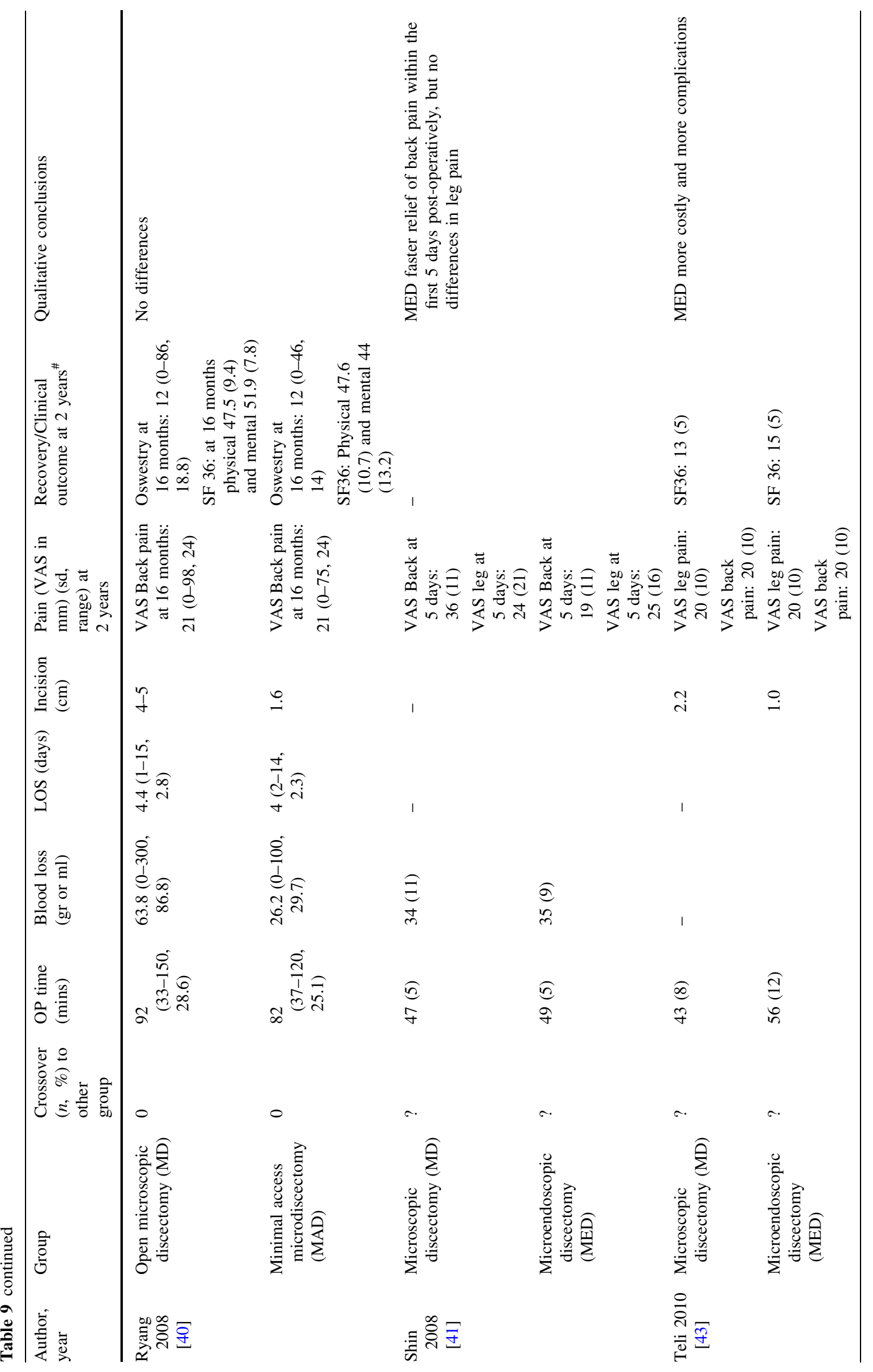




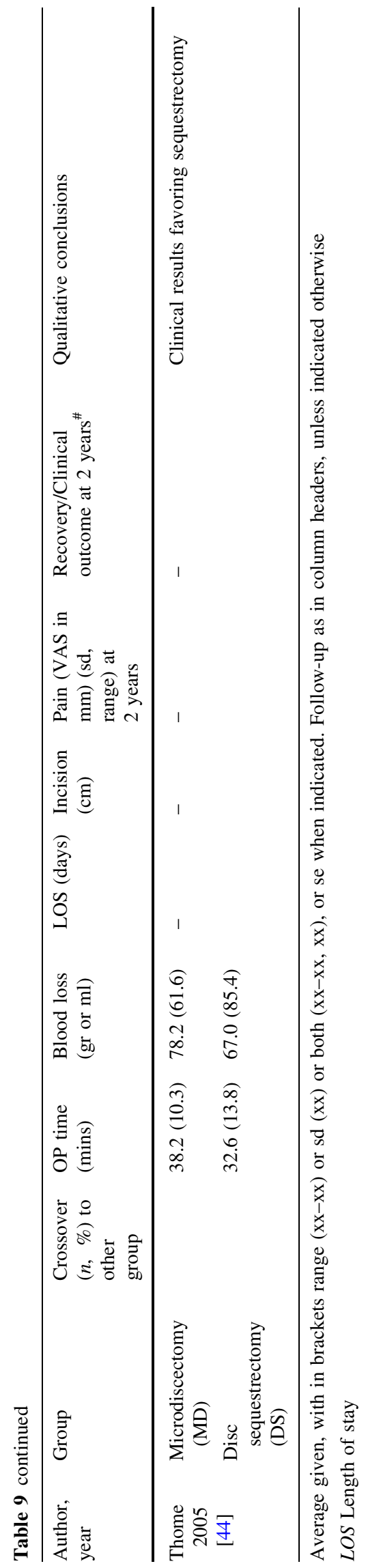

discharge to 24 months. Leg pain, Oswestry score, and SF36 scores could not be reliably estimated because of the few studies reporting these outcomes. In principle, the microscope provides better illumination and facilitates teaching. The choice of open or (type of) microscopic discectomy at present probably depends more on the training and expertise of the surgeon, and the resources available, than on scientific evidence of efficacy. However, it is worth noting that some form of magnification is now used almost universally in major spinal surgical units to facilitate vision. New techniques should only be used under controlled circumstances in a clinical trial that compares against microscopic discectomy, open discectomy or conservative interventions. Use of the more costly microsurgical techniques with comparable clinical outcomes would be justified if the advantages of reduced surgical morbidity were proven with at least an equal clinical outcome. A non-inferiority design would have been applicable to answer this question, but so far, has not been used, and test of non-inferiority was not anticipated in this review. A secondary cost-utility analysis on one trial comparing conventional versus MED [6] showed non-significant higher cost for the MED technique [47].

The place for other forms of discectomy is unresolved. Studies of automated percutaneous discectomy and laser discectomy suggest that clinical outcomes following treatment are at best fair and probably worse than after microscopic discectomy, although the importance of patient selection is acknowledged. There are no studies examining intradiscal electrotherapy, coblation or fusion as a treatment for sciatica due to disc herniation.

Many of the studies had major design weaknesses. For example, some of the studies had a very small sample size, which was only complicated by the fact that many of these had not performed a sample size calculation; therefore, the possibility for type II error cannot be ruled out. Methods and published details of randomization were often poor and there was lack of concealment of treatment allocation. Given the nature of surgical interventions, surgeon blinding was not possible. Blinded assessment of outcome was generally feasible yet often not even attempted. There were few clinical outcomes meeting standardized requirements [13]. It is remarkable that leg pain was only reported in about half of the studies, while this could be regarded as the main reason for performing surgery in these patients. Some of the assessments were made by the operating surgeon or by a resident or fellow beholden to the primary investigator, thus introducing assessor bias. Although most of the studies had follow-up rates of at least $90 \%$, there was often unclear early code break or crossover of patients not properly described, let alone allowed for in the analysis or presentation of results. These defects of study design introduced considerable potential for bias. Most of the conclusions of this review are based upon 6- to 12-month 
outcomes and there is a general lack of information on longer-term outcomes. Only a minority of the studies, especially the older ones, presented 2-year follow-up results as recommended for surgical studies.

To put our results into perspective, our systematic review was compared with the three reviews that studied different surgical techniques and which were published in 2009 [22, 36, 48]. These reviews have serious limitations in methodology. McGirt et al. [36] and Watters and McGirt [48] use the same search strategy and methodology and can be regarded as the same review with a different outcome parameter (overall outcome and recurrent disc herniation). Both randomized and non-randomized controlled trials as well as case series are included, thus making it difficult to decipher the effect of surgery. In both reviews there are conflict of interest issues [36, 48]. Both reviews do not use an accepted pooling method and should not be used for decision analysis. For example, McGirt et al. [36] include the comparative studies and the case series and analyze both study designs in the same analysis. Gotfryd and Avanzi [22] include ten (quasi-)randomized studies comparing classical discectomy, microdiscectomy, and/or endoscopic discectomy. They only evaluated randomization and allocation concealment as possible risk of bias items. This limits the possibility to assess the effect of other possible sources of bias in the comparisons, such as lack of blinding and poor attrition. They concluded that microsurgical and endoscopic techniques are only superior with regard to blood loss, hospital stay end systemic repercussions, but not for satisfaction, pain or other clinical parameters. To conclude, we believe our review produces reliable and valid results because no conflict of interest is present and the use of the Cochrane methods guarantees high quality.

\section{Conclusion}

Implications for practice: due to the limited amount and quality of evidence, no firm conclusions on effectiveness of the current surgical techniques, being open discectomy, microscopic discectomy, and tubular discectomy, compared with each other can be drawn. Those differences in leg or back pain scores, operation time, and incision length that were found are clinically insignificant. Therefore, the surgical strategy in the treatment of lumbar disc herniation should be based on preferences of patients and surgeons rather then outcome measures.

Implications for research: large, high-quality studies are needed, which examine not only effectiveness but costeffectiveness as well.

Acknowledgments This study was supported by a grant from the Dutch Health Insurance Council.

\section{Conflict of interest None.}

Open Access This article is distributed under the terms of the Creative Commons Attribution License which permits any use, distribution, and reproduction in any medium, provided the original author(s) and the source are credited.

\section{References}

1. NIH Clinical Trials database (2011) http://clinicaltrials.gov/. Accessed 1 Jun 2011

2. The International Standard Randomized Controlled Trial Number Register (ISRCTN) (2011) http://www.controlled-trials.com/. Accessed 1 Jun 2011

3. USFDA trial register, post approval studies (2011) http://www. accessdata.fda.gov/scripts/cdrh/cfdocs/cfPMA/pma_pas.cfm. Accessed 1 Jun 2011

4. Arts M, Brand R, van der Kallen B, Nijeholt G, Peul W (2011) Does minimally invasive lumbar disc surgery result in less muscle injury than conventional surgery? A randomized controlled trial. Eur Spine J 20(1):51-57

5. Arts MP, Brand R, Koes BW, Peul WC (2010) Effect modifiers of outcome of surgery in patients with herniated disc related sciatica? A subgroup analysis of a randomised clinical trial. J Neurol Neurosurg Psychiatry 81(11):1265-1274

6. Arts MP, Brand R, van den Akker ME, Koes BW, Bartels RH, Peul WC (2009) Tubular diskectomy vs conventional microdiskectomy for sciatica: a randomized controlled trial. JAMA 302(2): 149-158

7. Arts MP, Brand R, van den Akker ME, Koes BW, Bartels RH, Tan W, Peul WC (2011) Tubular diskectomy vs conventional microdiskectomy for the treatment of lumbar disk herniation: 2-year results of a double-blind randomized controlled trial. Neurosurgery 69(1):135-144

8. Barth M, Diepers M, Weiss C, Thome C (2008) Two-year outcome after lumbar microdiscectomy versus microscopic sequestrectomy: part 2: radiographic evaluation and correlation with clinical outcome. Spine (Phila Pa 1976) 33(3):273-279

9. Barth M, Weiss C, Thome C (2008) Two-year outcome after lumbar microdiscectomy versus microscopic sequestrectomy: part 1: evaluation of clinical outcome. Spine (Phila Pa 1976) 33(3):265-272

10. Brock M, Kunkel P, Papavero L (2008) Lumbar microdiscectomy: subperiosteal versus transmuscular approach and influence on the early postoperative analgesic consumption. Eur Spine $\mathbf{J}$ 17(4):518-522

11. Caspar W (1977) A new surgical procedure for lumbar disc herniation causing less damage through a microsurgical approach. In: Wullenweber R, Brocck M, Hamer J (eds) Advances in Neurosurgery. Springer, Berlin, pp 74-77

12. Chatterjee S, Foy PM, Findlay GF (1995) Report of a controlled clinical trial comparing automated percutaneous lumbar discectomy and microdiscectomy in the treatment of contained lumbar disc herniation. Spine (Phila Pa 1976) 20(6):734-738

13. Deyo RA, Battie M, Beurskens AJ, Bombardier C, Croft P, Koes B, Malmivaara A, Roland M, Von KM, Waddell G (1998) Outcome measures for low back pain research. A proposal for standardized use. Spine (Phila Pa 1976) 23(18):2003-2013

14. Deyo RA, Mirza SK (2006) Trends and variations in the use of spine surgery. Clin Orthop Relat Res 443:139-146

15. Foley K, Smith MM. (1997). Microendoscopic discectomy. Tech Neurosurg(3): 301-307

16. Franke J, Greiner-Perth R, Boehm H, Mahlfeld K, Grasshoff H, Allam Y, Awiszus F (2009) Comparison of a minimally invasive 
procedure versus standard microscopic discotomy: a prospective randomised controlled clinical trial. Eur Spine J 18(7):992-1000

17. Furlan AD, Pennick V, Bombardier C, van TM (2009) 2009 updated method guidelines for systematic reviews in the Cochrane Back Review Group. Spine (Phila Pa 1976) 34(18):1929-1941

18. Geisler FH (1999) Prevention of peridural fibrosis: current methodologies. Neurol Res 21(Suppl 1):S9-22

19. Gibson JN, Waddell G. (2005). Surgery for degenerative lumbar spondylosis. Cochrane Database Syst Rev (2): CD001352

20. Gibson JN, Waddell G. (2007). Surgical interventions for lumbar disc prolapse. Cochrane Database Syst Rev(2): CD001350

21. Gibson JN, Waddell G (2007) Surgical interventions for lumbar disc prolapse: updated Cochrane Review. Spine (Phila Pa 1976) 32(16):1735-1747

22. Gotfryd A, Avanzi O (2009) A systematic review of randomised clinical trials using posterior discectomy to treat lumbar disc herniations. Int Orthop 33(1):11-17

23. Gregory DS, Seto CK, Wortley GC, Shugart CM (2008) Acute lumbar disk pain: navigating evaluation and treatment choices. Am Fam Physician 78(7):835-842

24. Greiner-Perth R, Bohm H, ElSaghir H, El GA (2002) The microscopic assisted percutaneous approach to posterior spine-a new minimally invasive procedure for treatment of spinal processes. Zentralbl Neurochir 63(1):7-11

25. Guyatt GH, Oxman AD, Kunz R, Falck-Ytter Y, Vist GE, Liberati A, Schunemann HJ (2008) Going from evidence to recommendations. BMJ 336(7652):1049-1051

26. Haines SJ, Jordan N, Boen JR, Nyman JA, Oldridge NB, Lindgren BR (2002) Discectomy strategies for lumbar disc herniation: results of the LAPDOG trial. J Clin Neurosci 9(4):411-417

27. Haines SJ, Jordan N, Boen JR, Nyman JA, Oldridge NB, Lindgren BR (2002) Discectomy strategies for lumbar disc herniation: study design and implications for clinical research. J Clin Neurosci 9(4):440-446

28. Henriksen L, Schmidt K, Eskesen V, Jantzen E (1996) A controlled study of microsurgical versus standard lumbar discectomy. Br J Neurosurg 10(3):289-293

29. Hermantin FU, Peters T, Quartararo L, Kambin P (1999) A prospective, randomized study comparing the results of open discectomy with those of video-assisted arthroscopic microdiscectomy. J Bone Joint Surg Am 81(7):958-965

30. Huang TJ, Hsu RW, Li YY, Cheng CC (2005) Less systemic cytokine response in patients following microendoscopic versus open lumbar discectomy. J Orthop Res 23(2):406-411

31. Jacobs WC, van TM, Arts M, Rubinstein SM, van MM, Ostelo R, Verhagen A, Koes B, Peul WC (2011) Surgery versus conservative management of sciatica due to a lumbar herniated disc: a systematic review. Eur Spine J 20(4):513-522

32. Katayama Y, Matsuyama Y, Yoshihara H, Sakai Y, Nakamura H, Nakashima S, Ito Z, Ishiguro N (2006) Comparison of surgical outcomes between macro discectomy and micro discectomy for lumbar disc herniation: a prospective randomized study with surgery performed by the same spine surgeon. J Spinal Disord Tech 19(5):344-347

33. Lagarrigue J, Chaynes P (1994) Comparative study of disk surgery with or without microscopy. A prospective study of 80 cases. Neurochirurgie 40(2):116-120

34. Legrand E, Bouvard B, Audran M, Fournier D, Valat JP (2007) Sciatica from disk herniation: medical treatment or surgery? Joint Bone Spine 74(6):530-535
35. Mayer HM, Brock M (1993) Percutaneous endoscopic discectomy: surgical technique and preliminary results compared to microsurgical discectomy. J Neurosurg 78(2):216-225

36. McGirt MJ, Ambrossi GL, Datoo G, Sciubba DM, Witham TF, Wolinsky JP, Gokaslan ZL, Bydon A (2009) Recurrent disc herniation and long-term back pain after primary lumbar discectomy: review of outcomes reported for limited versus aggressive disc removal. Neurosurgery 64(2):338-344

37. Paul M, Hellinger J (2000) Nd-YAG (1064 nm) versus diode (940 nm) PLDN: a prospective randomised blinded study. Proceedings of the First Interdisciplinary World Congress on Spinal Surgery and related disciplines: 555-558

38. Peul WC, van Houwelingen HC, van den Hout WB, Brand R, Eekhof JA, Tans JT, Thomeer RT, Koes BW (2007) Surgery versus prolonged conservative treatment for sciatica. N Engl J Med 356(22):2245-2256

39. Righesso O, Falavigna A, Avanzi O (2007) Comparison of open discectomy with microendoscopic discectomy in lumbar disc herniations: results of a randomized controlled trial. Neurosurgery 61(3):545-549

40. Ryang YM, Oertel MF, Mayfrank L, Gilsbach JM, Rohde V (2008) Standard open microdiscectomy versus minimal access trocar microdiscectomy: results of a prospective randomized study. Neurosurgery 62(1):174-181

41. Shin DA, Kim KN, Shin HC, Yoon do H (2008) The efficacy of microendoscopic discectomy in reducing iatrogenic muscle injury. J Neurosurg Spine 8(1):39-43

42. Steffen R, Luetke A, Wittenberg RH, Kraemer J (1996) A prospective comparative study of chemonucleolysis and laser discectomy. Orthop Trans 20:388

43. Teli M, Lovi A, Brayda-Bruno M, Zagra A, Corriero A, Giudici F, Minoia L (2010) Higher risk of dural tears and recurrent herniation with lumbar micro-endoscopic discectomy. Eur Spine J 19(3):443-450

44. Thome C, Barth M, Scharf J, Schmiedek P (2005) Outcome after lumbar sequestrectomy compared with microdiscectomy: a prospective randomized study. J Neurosurg Spine 2(3):271-278

45. Tullberg T, Isacson J, Weidenhielm L (1993) Does microscopic removal of lumbar disc herniation lead to better results than the standard procedure? Results of a one-year randomized study. Spine (Phila Pa 1976) 18(1):24-27

46. Tureyen K (2003) One-level one-sided lumbar disc surgery with and without microscopic assistance: 1-year outcome in 114 consecutive patients. J Neurosurg 99(3 Suppl):247-250

47. van den Akker ME, Arts MP, van den Hout WB, Brand R, Koes BW, Peul WC (2011) Tubular diskectomy versus conventional microdiskectomy for the treatment of lumbar disk related sciatica: cost utility analysis alongside a double-blinded randomized controlled trial. Neurosurgery 69(4):829-835

48. Watters WC III, McGirt MJ (2009) An evidence-based review of the literature on the consequences of conservative versus aggressive discectomy for the treatment of primary disc herniation with radiculopathy. Spine J 9(3):240-257

49. Williams RW (1978) Microlumbar discectomy: a conservative surgical approach to the virgin herniated lumbar disc. Spine (Phila Pa 1976) 3(2):175-182

50. Yasargil M (1977) Microsurgical opertion of the herniated lumbar disc. In: Wullenweber R, Brocck M, Hamer J (eds) Advances in Neurosurgery. Springer, Berlin, pp 81-84 